\title{
Patients' conceptions of their own influence on good treatment response to biological therapy in chronic inflammatory arthritis
}

This article was published in the following Dove Press journal:

Patient Preference and Adherence

26 June 2017

Number of times this article has been viewed

Ingrid Larsson ${ }^{1,2}$

'School of Health and Welfare, Halmstad University, ${ }^{2}$ Spenshult Research and Development Center, Halmstad, Sweden
Correspondence: Ingrid Larsson School of Health and Welfare, Halmstad University, Box 823, S-301 I8 Halmstad, Sweden

Tel +4635I67965

Email ingrid.larsson@hh.se
Background: Biological therapies are common in the treatment of patients with chronic inflammatory arthritis (CIA). However, despite the fact that many patients respond well to their biological therapies, there are still a number of nonresponders. In order to design the best care for patients, it is important to understand how they conceive their own role in their treatment response.

Objective: To explore how patients with CIA conceive their own influence on a good treatment response to biological therapy.

Methods: This study had an exploratory and descriptive design with a phenomenographic approach. Interviews were conducted with 25 patients ( 11 women and 14 men) aged 17-79 years, with CIA who were undergoing biological therapy and who had low disease activity or were in remission.

Results: Patients with CIA undergoing biological therapy conceived their own influence on good treatment response in terms of adherence, physical activity, mental attitude, social support, and self-awareness. Adherence was described as the foundation for the patients' own influence on good treatment response. Physical activity, mental attitude, and social support reflected three essential ways of understanding patients' influence on good treatment response where the patients spoke about physical strength, mental strength, and social strength. Self-awareness reflected a comprehensive way of influencing good treatment response in which patients balanced their physical, mental, and social resources in partnership with health care professionals.

Conclusion: Patients conceived that they had a responsibility for adhering to the treatment as well as achieving balance in life in order to ensure good treatment response. Self-awareness was essential for maintaining a good treatment response, and this reflected the patients' awareness of the complexity of living their lives with a chronic illness.

Keywords: biological therapy, chronic inflammatory arthritis, conceptions, good treatment response, phenomenography

\section{Introduction}

Living with chronic inflammatory arthritis (CIA) affects patients' physical functioning, but there are also emotional, psychological, and social aspects that have a global impact on the patients' life situations. ${ }^{1}$ The term CIA is an umbrella term for rheumatoid arthritis (RA) and spondyloarthritis (SpA) along with a number of sub-diagnoses. ${ }^{2}$ It is important for patients with CIA to receive an early diagnosis in order to receive timely and effective treatment, and it is important for the patients to undergo regular evaluations of disease activity. The primary goals of CIA treatment are to suppress disease activity and to achieve remission or low disease activity by controlling the 
symptoms and inflammation in order to prevent joint damage and early death..$^{3-5}$

Rheumatology research over the past two decades has led to the development of biological therapies for patients who have an inadequate response to conventional therapies, and these new therapies have completely changed the therapeutic arena. ${ }^{6}$ These biological therapies have been shown to be safe and effective in controlling the inflammatory symptoms of $\mathrm{RA}^{4}$ and $\mathrm{SpA},{ }^{3,5}$ and there is now a wide range of different biological therapies available for individually optimized treatment for each patient. Fairly high levels of adherence for biological therapies have been reported compared to conventional therapies for patients with CIA. ${ }^{7}$ Adherence to biological therapy increases when patients understand their illness and treatment control, believe in the necessity of the treatment, and are not seriously concerned about the treatment. ${ }^{8}$ Depending on the magnitude of change and level of disease activity obtained, treatment response is classified as none, moderate, or good treatment response. ${ }^{9}$ Disease activity is evaluated by several composite measurement instruments, including the Disease Activity Score 28 (DAS28), which consists of both objective and subjective assessments. ${ }^{10}$ The DAS28 is scored from 0 to 10 , where the values $>5.1,<5.1->3.2,<3.2-2.6$, and $<2.6$ indicate high disease activity, moderate disease activity, low disease activity, and remission, respectively. The European League Against Rheumatism classifies good treatment response as DAS28 $\leq 3.2$ with reductions in DAS28 of more than 1.2 points. ${ }^{11}$ Patients with good treatment response achieve an improvement in physical function and quality of life. ${ }^{12}$ Despite the fact that many patients respond well to their biological therapies, about one-third are nonresponders. ${ }^{6,13,14}$

Biological therapies are administered as subcutaneous injections or intravenous infusions. ${ }^{6}$ Patients who receive intravenous infusions tend to see the regular contact with a rheumatology nurse as secure, invigorating, and leading to involvement. ${ }^{15}$ On the other hand, patients performing selfadministration of subcutaneous injections describe a striving for independence, and some patients report missing regular contact with a nurse. ${ }^{16}$ Patients' values, preferences, and life situations in the treatment must be taken in account in order to achieve the best care, ${ }^{17}$ and collaboration with health care professionals is essential for enhancing quality of care if the patients have the capacity and desire to engage in such collaboration. ${ }^{18}$ This entails two-way communication between the patient and the members of the multidisciplinary team in terms of the treatment target, management plans, and support for the patients to develop their own personal preferences. ${ }^{3-5}$
The dialogue should be built on a partnership, and options should be considered in light of the values, preferences, and contexts of each patient's life situation. It is important for patients with chronic diseases that the focus of care is on the individual rather than on the illness, and the best course of action for one particular patient might not be the same for another. ${ }^{19}$ In order to design the best care for patients, it is important to understand their conceptions of being part of their treatment response. A literature review revealed that no study of rheumatology care has been performed that focuses on how patients conceive their influence on good treatment response. Knowledge of patients' conceptions of their influence on good treatment response is thus needed in order to shed light on other aspects of this complex phenomenon.

The aim of the study was thus to explore how patients with CIA conceive their own influence on a good treatment response to biological therapy.

\section{Methods \\ Design}

This study had an exploratory and descriptive design with a phenomenographic approach ${ }^{20}$ and was part of a larger research project that included a randomized controlled trial $(\mathrm{RCT})^{21}$ and a cost comparison study. ${ }^{22}$ The purpose of the larger research project was to convert one of the two annual biological monitoring visits with a rheumatologist to a nurse-led rheumatology visit for patients with stable CIA. The patients were monitored by a rheumatologist at baseline and monitored for 30 minutes by a rheumatology nurse after 6 months, and this was followed by 30 minutes of monitoring by a rheumatologist after 12 months. The nurse assessed the patients' disease activity in the same way as the rheumatologist. The patients in the control group were monitored for 30 minutes by a rheumatologist at baseline, 6 , and 12 months. ${ }^{21}$

A phenomenographic approach was chosen to describe the variations in how the participants conceived their influence on good treatment response. The goal of the phenomenographic approach is to discern how people experience, understand, or conceive a phenomenon in the world around them. The research is not directed at the phenomenon as such but at the variations in people's ways of understanding the phenomenon, and it seeks to describe the qualitatively different ways in which a group of people makes sense of, conceive, and understand the phenomenon. The idea of variation is important because people's conceptions differ depending on their relationship to the world. The phenomenographic analysis focuses on differences and similarities 
between and within people's statements because such statements indicate their conceptions of the phenomenon. ${ }^{20,23}$ These different ways of conceiving or understanding form descriptive categories, ${ }^{24,25}$ which refer to a collective level and describe the different ways the phenomenon can be understood. The descriptive categories form the outcome space and constitute the results of a phenomenographic study. ${ }^{23}$ Theoretically, a phenomenon can be conceived in an endless number of ways, but in the process of creating meaning, usually only 2-6 conceptions or ways of understanding will remain. ${ }^{26}$

\section{Participants}

Interviews were conducted with 25 of the 107 participants in the RCT study in the larger research project, which was conducted in the southern part of Sweden. ${ }^{21}$ Previous phenomenographic research has shown that data from about 20 informants are usually sufficient to discover all of the different experiences, conceptions, and ways of understanding the phenomenon in question. ${ }^{26}$ All the participants had stable CIA with low disease activity or were in remission. The patients' DAS28 were all $\leq 3.2$, which in this study was defined as good treatment response to biological therapy. In order to achieve variations in conceptions, a strategic sampling was used in terms of sex, age, civil status, education, diagnosis, disease duration, and duration and method of administration of biological therapy (Table 1), which is in accordance with the phenomenographic tradition. ${ }^{23}$

\section{Data collection}

Data collection took place during the RCT between October 2009 and August 2011 at a rheumatology clinic in southern Sweden. Oral and written information was provided, and when a patient gave informed consent, an agreement was reached regarding the time and location for the interview. The author performed the interviews in a quiet room at the clinic. The patients were guaranteed confidentiality and were informed that they could withdraw at any time without any explanation or consequences for their future care. The interviews were conducted in Swedish and started by stating, "Please tell me how you conceive your own influence in the good treatment response". In order to obtain comprehensive descriptions, follow-up requests were posed such as "Describe your own part in the good treatment response" or "Please tell me more". Another way to obtain extensive descriptions was repetition of what the participant had just said, or probing for explanations, such as asking "How",
Table I Sociodemographic and clinical data of the included patients

\begin{tabular}{ll}
\hline Characteristics & Participants (N=25) \\
\hline Sex & 1 I \\
Female & 14 \\
Male & \\
Age (years) & $17-79$ \\
$\quad$ Range & 52 \\
Mean & \\
Civil status & 16 \\
Married/cohabiting & 9 \\
Living alone & \\
Education level & 4 \\
9-year primary school & 11 \\
Secondary level education & 10 \\
College/university & \\
Diagnosis & 15 \\
$\quad$ Rheumatoid arthritis & 5 \\
Psoriatic arthritis & 5 \\
Spondyloarthritis & \\
Administration of biological therapy & 10 \\
Intravenous infusion & 15 \\
Subcutaneous injection & $1-42$ \\
Disease duration (years), range & $0.6 \mathrm{I}-2.88$ \\
Disease activity (DAS28 score), range & $0.25-10$ \\
Biological therapy duration (years), range &
\end{tabular}

Abbreviation: DAS28, Disease Activity Score 28.

"What do you mean when you say", or "What do you have in mind when you say". The interviews lasted from 30 to 60 minutes and were recorded and transcribed verbatim by the author, who is familiar with the interview technique. The descriptive categories and the quotations that illustrate the results were translated from Swedish to English by a native English speaker.

\section{Data analysis}

In accordance with the phenomenographic approach, the analysis was performed on the basis of two contexts - the individual interviews and extracts from all interviews that dealt with the phenomenon under study. ${ }^{23}$ The data analysis was conducted in Swedish by the author in a seven-step process according to Dahlgren and Fallsberg and Sjöström and Dahlgren. ${ }^{24,27}$ The first step, familiarization, meant that each interview was listened to and the transcripts were read several times in order to become familiar with the material and to obtain an overall impression of the data. In the second step, condensation, the author tried to identify significant statements related to the aim of the study. These statements were entered into a table in the computer that clearly indicated the interview from which they originated. The statements were then condensed in order to provide a 
short, but representative, version of the entire interview with regard to the subject's conception of their own influence on a good treatment response. The third step of the analysis involved comparison of significant statements in order to identify differences and similarities in the statements. In the fourth step, grouping, the statements were grouped on the basis of their characteristic properties in order to obtain a deeper understanding of the way in which they were connected and formed the patients' conceptions. In the fifth step, articulating, a preliminary attempt was made to describe the essence of each group and to establish borders between the preliminary categories and to ensure that these were distinct and qualitatively separated. The analysis moved back and forth between the fourth and fifth steps, and this led to five descriptive categories. In the sixth step, labeling, each descriptive category was labeled with a suitable description. Finally, in the seventh step, contrasting, the descriptive categories were compared in terms of similarities and differences on a more abstract level in order to structure the outcome space and to clarify the internal relationships between the descriptive categories. The outcome space constituted the structure of the variation in conceiving the phenomenon of the patient's own influence on a good treatment response.

The author has extensive experience in both rheumatology and qualitative methods, especially in the phenomenographic approach. However, to increase trustworthiness in the study, a professor with extensive experience in the phenomenographic methodology acted as an independent coassessor during the data analysis. A process called "negotiating consensus" was used to reach agreement about the final descriptive categories and the internal relationships between the descriptive categories, ie, the outcome space. ${ }^{28}$

\section{Ethics}

This research conforms to the ethical principles for medical research on human beings set out in the Declaration of Helsinki, including autonomy, beneficence, non-maleficence, and justice, and it fulfills the four research requirements of information, consent, confidentiality, and safety of the participants. ${ }^{29}$ Patients received oral and written information about the study and the voluntary nature regarding participation and their right to withdraw at any time. Written informed consent was obtained from all of the patients prior to their inclusion in the study. Permission was obtained from the Regional Ethical Review Board at Lund University, Sweden (numbers 2008/594 and 2009/245).

\section{Results}

Patients with CIA with low disease activity or in remission and undergoing biological therapy conceived their own influence on good treatment response in terms of adherence, physical activity, mental attitude, social support, and self-awareness. These different ways of understanding formed an outcome space of five descriptive categories that characterized the variation in patients' conception of their own influence on good treatment response. Quotations from the participants' descriptions are used in this text to provide illustrative examples of the descriptive categories.

\section{Good treatment response influenced by adherence}

In this descriptive category, the participants conceived their own influence on good treatment response in terms of adherence to prescriptions, which was a prerequisite for maintaining good treatment response. They trusted in their rheumatologist's prescriptions of medication and emphasized the importance of being adherent.

The doctor is a specialist so [...]. I completely trust that what he says is right. [Informant 2]

The participants conceived that participation in the decision-making about their therapy was important. The decision to participate was preceded by a dialog between the rheumatologist and the patient, which was a reason for being adherent to the treatment prescription. The good treatment response was also in turn a contributory factor to the participants' motivation for adherence.

If I take my medication, then I'll feel good. My role in treatment being good is to see that I have new prescriptions and that the medication is available at the pharmacy when I need it. There's quite a lot to keep track of! [Informant 15]

Good treatment response influenced by adherence was described as a partnership between the patient and the rheumatologist. In the partnership, the rheumatologist was the expert on disease and treatment, while the patient was the expert on the administration of the subcutaneous injections. The patients had routines for achieving adherence and thus good treatment response.

I'm a part of it [the good treatment response] through me taking my injections and keeping to my medication schedule [...]. My cooperation with my rheumatologist is good, and they know all about the medications and other things. [Informant 17] 


\section{Good treatment response influenced by physical activity}

In this descriptive category, the participants conceived their own influence on good treatment response in terms of being physically active. A good physique and a healthy physical lifestyle were conceived of as prerequisites for maintaining good treatment response. This included both a reduction of disease activity and a reduction of symptoms, such as less pain, which increased mobility. The participants spoke of being able to influence the good treatment response through physical exercise.

Because I exercise, I'm well aware that physical training is very important. Even if there's been times when I've been in great pain, I've still tried to carry on exercising. [Informant 8]

The participants described the importance of physical activity in good treatment response. They saw themselves as being responsible for their own well-being, which they could influence by being physically active. It was emphasized that physical activity should be individually tailored to each patient's circumstances.

But I feel better by keeping myself active, doing something, and then I might do it more often during the spring, summer, and autumn [...] but of course I'm able to influence this myself and how I feel. If I were to just sit down, then I'd have more pain of course. That's how I think, and how active one is and how much pain one has varies from person to person [...]. So, I think I've got a major part to play in this [...]. There's a great responsibility on my shoulders of course. [Informant 11]

A good treatment response was also conceived as being a balance between physical activity and relaxation. The participants described a positive upward spiral being created in the balance between various types of physical activities and relaxation. Good treatment response and physical activity had a mutual effect on each other, and the participants conceived that good treatment response influenced their ability to be physically active and that physical activity influenced the good treatment response.

If the treatment works well, then one feels better. If one feels better, then one can be more active. And if one is more active, then there'll also be a more positive progress with the illness. My spiral is on the way up, and that's good [...] I notice a positive result from the treatment, from feeling better, more alert, more active at work and at home [...] and one becomes more relaxed towards the illness [...] physical energy is released and suddenly you're more active. [Informant 22]

\section{Good treatment response influenced by mental attitude}

In this descriptive category, the participants conceived their own influence on good treatment response in terms of having a positive mental attitude, where an optimistic view of life was important and a positive attitude toward the treatment was a prerequisite for maintaining good treatment response.

One's attitude, of course. Oh my goodness, how jaunty

I sound $[\ldots]$ but that's my basic attitude $[\ldots]$ but I think that one can do a lot [with a positive attitude]. [Informant 11]

The participants described the importance of one's mental attitude in good treatment response. They found strength in positive thoughts, and this influenced their well-being. It was emphasized that having a positive attitude was a foundation for, and an important part of, a wholeness that positively influences people both mentally and physically.

One can try to control one's thoughts a little and influence them oneself because it's possible to do. Then I think that one can, then one has the possibility, then one has done something to be able to feel better [...] it's like a circle. Everything, one's soul and body, are linked in some way, I think, so that if you feel good in the soul then there's a greater chance to feel good physically. [Informant 24]

Good treatment response influenced by a mental attitude was furthermore described as a strength of the mind. An open mind and a positive attitude were conceived as powerful factors that facilitate life with a chronic disease and with what are often lifelong treatments.

Being so open and having an open mind; a positive attitude is perhaps also very important. I have a positive attitude to life and my treatment [...]. I think it's easier to live when one has a positive attitude. I practice Qigong and balance energies, and that might also influence the fact that the medication works better. [Informant 5]

\section{Good treatment response influenced by social support}

In this descriptive category, the participants conceived their own influence on good treatment response in terms 
of having social support in different contexts. Social support from family, friends, and colleagues was conceived as essential in influencing good treatment response, and an important part of social support was having regular conversations with other people. Commitment and participation from the family constituted another vital part of the social support for the patient in the treatment response. A close relationship with relatives such as one's spouse, partner, children, or grandchildren had a positive influence on good treatment response.

Social support at home, I've been married to the same woman since $[\ldots]$, and we have three adult sons today. That's also an important part that one needs. I think you understand what I mean. [Informant 8]

The participants described the importance of social networks and relationships with friends or other patients. The exchange of information between patients was conceived as a form of social support, and sharing experiences and learning from each other influenced good treatment response and increased their knowledge.

One can gather information by talking to others [...] and listening to how they are. And sometimes one can hear what they do to feel better and what type of help is available. [Informant 24]

Good treatment response was also influenced by social contacts with colleagues or clients at work. Working confirmed the patient's professional expertise and created meaning in the patient's life, and being part of a workplace was described as important for the social support that influenced good treatment response.

Going to work every day. I've actually been better when I've gone to work because you have something else to think about. If you just lie in bed, you only think of the illness. No, I've not felt bad doing that [going to work each day]. [Informant 2]

\section{Good treatment response influenced by self-awareness}

In this descriptive category, the participants conceived their own influence on good treatment response in terms of having self-awareness, which was essential for maintaining the desired level of treatment response. The participants described how to master their lives by listening to their body's signals, despite some adaptation to the disease and to their treatment. However, they had learned to recognize their body's signals and had thus taken control of their lives.
One has to organize one's life after them [the illness and the treatment] the little control that the illness can have over me. But the rest I can take care of myself. If I can't walk then I'll cycle instead [...] now I've learned, I live with it in a different way, especially now when I can move more and can have a more dignified life. Then I know how much I can push myself [...]. I've got to know my body and take part in my treatment, yes, I'm sure of that. [Informant 21]

The participants described the importance of selfawareness as a prerequisite for maintaining a good treatment response and thus having control over their own lives. Focusing on meaningful activities at home and at work and not thinking about the disease contributed to good treatment response. Moreover, the participants were involved in their good treatment response by being self-aware when managing situations such as a relapse or infections where the treatment needed to be adjusted or temporarily suspended.

\begin{abstract}
But if you always focus on your illness, then it is the illness that dominates your life. I have to take a number of things into consideration, but otherwise I only focus a little on my illness. I focus on my job and my time at home, etc. [...] then you have to regulate things a lot yourself, for example, if I feel that I have an infection [...] then I wait till it's gone [skipping the subcutaneous injection] I'm quite sure of myself. [Informant 8]
\end{abstract}

Good treatment response influenced by self-awareness was furthermore conceived as a way of finding balance in one's life. Self-awareness was conceived as necessary for balancing physical activities, mental attitude, and social support in order to achieve well-being. The participants emphasized the importance of personal responsibility in creating balance in their lives. They described it as each patient having a personal responsibility for his or her own life and also treatment response. The patient should thus be the one who invites the health care professionals to participate in their care and not the other way around.

Life is a balancing act. You can't do too little otherwise you'll feel bad. You can't do too much as you'll be bad, then, too. You have to find your own balance [...]. This balance is fantastic because when you are balanced, then you feel very good. You find a balance between medication and movement, and you are the only one who can do that. That is where participation is, or it is the healthcare services that participate. I'm the one who is responsible, 
and thus the healthcare services have to participate [...]. It is actually my life. I can't participate in my life, but I have to be responsible for it. [Informant 5]

\section{Outcome space}

The outcome space reflected the internal relations between the five descriptive categories, and a hierarchy (Figure 1) could be structured that represents the patients' collective conceptions of their own influence on good treatment response. In analyzing the outcome space, the common characteristics of all of the descriptive categories created a picture of different actions being performed by a holistic human being, which together could influence the complex phenomenon of good treatment response.

Adherence is at the base of the hierarchy, as shown in Figure 1, because it was described as the foundation of the patients' own influence on good treatment response, and the patients spoke about adherence as their responsibility for participating in their treatment. Physical activity, mental attitude, and social support are on the same level in the hierarchy, as shown in Figure 1, because these reflect three essential ways of understanding the patients' influence on good treatment response in which patients talked about physical strength, mental strength, and social strength. Self-awareness is at the top of the hierarchy, as shown in Figure 1, because it encompasses the ability to engage in and take full advantage of all of the other personal factors that support a good treatment response. Self-awareness reflected a comprehensive way of supporting a good treatment response in which patients were aware of the balance between their physical, mental, and social resources and their partnership with health care professionals. This category was interpreted as reflecting the patients' awareness of the complexity of the relationship between their chronic illness and other parts of their lives. This suggests that good treatment response from biological therapy in CIA was not conceived as being dependent simply on the rheumatologist's prescription of biological therapy, but rather as a set of complex interactions in which the patient plays a unique role as a coactor.

\begin{tabular}{|l|l|l|}
\hline \multicolumn{3}{|c|}{ Good treatment response influenced by self-awareness } \\
\hline $\begin{array}{l}\text { Good treatment } \\
\text { response influenced } \\
\text { by physical activity }\end{array}$ & $\begin{array}{l}\text { Good treatment } \\
\text { response influenced } \\
\text { by mental attitude }\end{array}$ & $\begin{array}{l}\text { Good treatment } \\
\text { response influenced } \\
\text { by social support }\end{array}$ \\
\hline \multicolumn{2}{|c|}{ Good treatment response influenced by adherence } \\
\hline
\end{tabular}

Figure I The outcome space - the patients' collective understanding of their own influence on good treatment response and the relationship between the descriptive categories.

\section{Discussion}

Living with chronic diseases such as CIA entails patients having to struggle to manage their lives, which includes a constant consideration of disease symptoms and drug treatments. There is a need to maintain balance in one's life in order to reduce the impact of the disease and its treatments, ${ }^{30}$ and a good treatment response is therefore important for these patients. This phenomenographic study shows how patients conceive their own influence on good treatment response through adherence, physical activity, mental attitude, social support, and self-awareness.

Adherence to prescriptions is a prerequisite for good treatment response. ${ }^{7}$ The participants in this study described adherence as a foundation for good treatment response, and they trusted their rheumatologist's prescriptions. However, they emphasized the importance of a dialog between rheumatologists and patients in the decisions concerning treatment therapy. The participants stated that treatment adherence was based on a partnership between the rheumatologist and the patient, and this is consistent with previous research indicating the importance of including the patient's perspective in the decision-making about treatment therapy in order to increase adherence. ${ }^{31}$ Bolge et al reported a difference between what patients with CIA preferred in terms of the administration of treatments and the attributes of biological therapies from what rheumatologists thought patients would prefer. There was also a discrepancy between what patients and rheumatologists perceived as having been discussed regarding their treatments. The rheumatologists reported having discussions with the patients, while the patients were not aware of such discussions having taken place in the same way. ${ }^{32}$ By contrast, another study showed that the preferences of patients and rheumatologists were consistent in terms of the attributes of biological therapies. ${ }^{33}$ In order to attain good treatment response through adherence, it is necessary to have a dialog in order to understand the patient's preferences and beliefs about biological therapy and to involve them in shared decision-making. ${ }^{7,34,35}$ Shared decision-making and skills in managing treatment therapy require a knowledge and an understanding of the therapy's effect on the disease and the impact that the therapy can have on the patient's life. Patient knowledge of treatment therapy might enhance the tolerability of the therapy and thereby enhances adherence. Thus, an informed patient is a prerequisite for a partnership between the patient and the health care professionals that is based on equal terms. ${ }^{36}$

The participants in this study conceived that physical activity influenced good treatment response with reduced 
disease activity and fewer symptoms such as less pain and less stiffness. This interaction between good treatment response and physical activity was described as an upward spiral that was related to a balance between physical activity and relaxation and to individually tailored physical exercise regimens. One explanation for this might be that regular physical exercise has been shown to have anti-inflammatory effects, which is important for good treatment response in patients with CIA. ${ }^{37,38}$ Another explanation might be that a low level of disease activity with fewer symptoms in the patients included in this study contributed to increased opportunities for these patients to be physically active. Research shows that there is a relationship between physical activity and disease activity, and patients with a low level of disease activity tend to be more physically active. ${ }^{38-40}$ Furthermore, it is also important to be aware of patients' beliefs about the positive effect of physical activity in reducing their symptoms, ${ }^{41}$ and it has been found in several qualitative studies that patients emphasize the importance of physical activity in the management of their CIA and as a way of maintaining control over their symptoms and their lives and of being independent. ${ }^{42,43}$ Feelings of pain relief, improvements in joint function, and increased energy from physical activities are reported to have a positive impact on patients' daily lives ${ }^{43}$ and to lead to feelings of greater freedom and strength in the body. ${ }^{44}$

The participants in this study conceived that mental attitude in terms of an optimistic view on life and a positive attitude toward treatment influenced good treatment response. Evidence regarding the influence of positive mental factors such as optimism in treatment response for patients with CIA is scarce. ${ }^{45}$ There is, however, a study that indicates that perceptions of treatment control are related to a positive outlook in patients with a low level of disease activity, ${ }^{46}$ and in a recent study, patients with CIA ranked the importance of keeping a positive attitude as high. ${ }^{47}$

Social support for patients with CIA includes support from family, health care professionals, and significant others, which means people with sufficient importance in an individual's life, ${ }^{48}$ and in this study, the participants conceived that social support influenced good treatment response. Commitment and participation from family, friends, and colleagues as well as other patients contributed to a feeling of being important and created meaning in the patient's life. Research reveals that commitment and participation from family and friends in the course of biological therapy increase patients' motivation to adhere to the treatment and thus to achieve good treatment response. ${ }^{8,49}$ This is strengthened by other research that has shown that one reason for patients with CIA discontinuing biological therapy is a lack of social support. ${ }^{50}$ Studies show that social support is important for patients with CIA in terms of not only managing the treatment but also managing everyday life. This social support has to be tailored to the patient's individual needs, both at home and at work. ${ }^{51}$

Finally, the participants in this study conceived that good treatment response was influenced by self-awareness. They have mastered their lives by adapting to the disease and treatment, and they listen carefully to their body's signals with the intention of taking control over their own lives. The participants prioritized meaningful activities as influencing their well-being, and they emphasized the importance of finding a balance between different activities. They highlighted their personal responsibility for achieving balance in their life and thus achieving good treatment response. Research shows the importance of having a person-centered approach because the proper balance of life activities is perceived as influencing symptoms such as pain and fatigue. ${ }^{52-54}$ Self-awareness in patients with CIA also includes the balance between physical, mental, and social needs for enhancing well-being. ${ }^{55}$ These patients describe self-awareness as being aware of the body and using personal resources in order to find a balance between managing their disease and their treatment and carrying out the activities of their daily lives. ${ }^{30,56-58}$ Health care professionals can support patients in balancing the daily activities in life, and person-centered care, in which an individual patient is seen as a unique person with physical, mental, and social needs, facilitates this. ${ }^{53,59}$ The participants in this study emphasized the importance of taking control over their lives, and thus, the patient should be the one who invites the health care professionals to participate in their care and not the other way around.

\section{Methodological considerations}

In qualitative research, trustworthiness is defined according to the four criteria of credibility, dependability, confirmability, and transferability. ${ }^{60,61}$ Credibility refers to confidence in the truth of the data and the analysis. ${ }^{61}$ The aim of a phenomenographic approach ${ }^{20,23}$ is to identify variations, and credibility was strengthened in this study through the strategic selection of participants. In this study, there were 25 purposefully included patients with CIA undergoing biological therapy with a low level of disease activity or in remission who varied in terms of sex, age, education, diagnosis, disease duration, and duration and method of administration of biological therapy. Credibility was furthermore strengthened by the researcher's familiarity with the methodology and the careful 
descriptions provided regarding data collection and analysis in this study. The categories were compared and revised until the final classification emerged. Dependability refers to the stability of data over time and conditions ${ }^{61}$ Dependability was strengthened by the fact that all interviews began with the same opening question in order to ensure stability of the data and to facilitate comparisons between the interviews. Follow-up questions were posed to avoid misunderstanding, and the participants were encouraged to talk openly. The interviews took place in a quiet location chosen by the participants. The same researcher conducted and transcribed the interviews, which can be considered as both a strength and a weakness. The strength was that the interviews were conducted in the same way, while the weakness was that the interviewer gained new insight into the phenomenon over the course of the interviews, which might have influenced the follow-up questions. Thus, in order to increase dependability, a coassessor who was familiar with the methodology also compared and revised the categories until the final classification emerged. This negotiating consensus between multiple assessors to increase dependability is an integral part of the phenomenographic approach. ${ }^{24,27,28}$ Confirmability refers to the neutrality of the data, which ensures that the data represent the information provided by the participants and accurately reflect their voices. ${ }^{61}$ Confirmability was demonstrated by the systematic and careful treatment of the data, including repeated reading and identification of and reflection on the content. All steps of the analysis have been carefully reported. The participants' conceptions were described in as much detail as possible, and quotations enhance and illuminate the content. A limitation could be the duration of the interviews, and 30-60 minutes might have been too short. However, the interview texts were deemed to be rich in content and to contain a great variety of statements and ideas. ${ }^{27}$ Transferability refers to the applicability of the results to other contexts. ${ }^{61}$ Because the strategic selection included purposeful variations within the group of patients with stable CIA undergoing biological therapy with good treatment response, the results are likely to be transferable to patients with other chronic diseases with low disease activity or in remission. A limitation might be that all participants in the study were patients at the same clinic. Nevertheless, the sample size can be regarded as sufficient to ensure variation in conceptions of the same phenomenon. ${ }^{20,23}$

\section{Conclusion}

The results of this study provide a better understanding of the complex phenomenon of good treatment response to biological therapy from the patients' perspective. Selfawareness and a balance between physical activity, mental attitude, and social support as well as adherence to the treatment are aspects conceived as influencing good treatment response. Patients conceived that they had a responsibility for adhering to the treatment as well as for achieving balance in their life and thus for achieving good treatment response. Self-awareness was essential for maintaining good treatment response and reflected the patients' awareness of the complex interplay between their daily lives and chronic illness. This suggests that good treatment response to biological therapy in CIA was not conceived as a passive action depending only on the rheumatologist's prescription of biological therapy, but rather as a complex interplay in which the patients were coactors in partnership with health care professionals. Even for patients with CIA who have low disease activity or are in remission, there is still a need for both clinical and research interventions regarding physical and mental training as well as self-awareness. It would be interesting to assess the correlation between the results of these interventions and a good treatment response. Further prospective studies are needed to evaluate how the individual factors of adherence, physical activity, mental attitude, social support, and self-awareness affect good treatment response in a large cohort of patients with CIA undergoing biological therapy.

\section{Acknowledgment}

The author thanks all of the participants for so willingly sharing their experiences. A special thanks to Professor Emeritus Barbro Arvidsson for acting as the coassessor during the data analysis.

\section{Disclosure}

The author reports no conflict of interest in this work.

\section{References}

1. Hewlett S, Chalder T, Choy E, et al. Fatigue in rheumatoid arthritis: time for a conceptual model. Rheumatology (Oxford). 2011;50(6): 1004-1006.

2. van Eijk-Hustings Y, van Tubergen A, Boström C, et al. EULAR recommendations for the role of the nurse in the management of chronic inflammatory arthritis. Ann Rheum Dis. 2012;71(1):13-19.

3. Gossec L, Smolen JS, Ramiro S, et al. European League Against Rheumatism (EULAR) recommendations for the management of psoriatic arthritis with pharmacological therapies: 2015 update. Ann Rheum Dis. 2016;75(3):499-510.

4. Smolen JS, Landewé R, Bijlsma J, et al. EULAR recommendations for the management of rheumatoid arthritis with synthetic and biological disease-modifying antirheumatic drugs: 2016 update. Ann Rheum Dis. 2017;76(6):960-977.

5. van der Heijde D, Ramiro S, Landewé R, et al. 2016 Update of the ASASEULAR management recommendations for axial spondyloarthritis. Ann Rheum Dis. 2017;76(6):978-991. 
6. van Vollenhoven RF. New therapeutic approaches in rheumatoid arthritis. Presse Med. 2016;45(6 Pt 2):e179-e192.

7. Barton JL. Patient preferences and satisfaction in the treatment of rheumatoid arthritis with biologic therapy. Patient Prefer Adherence. 2009;3:335-344.

8. Morgan C, McBeth J, Cordingley L, et al. The influence of behavioural and psychological factors on medication adherence over time in rheumatoid arthritis patients: a study in the biologics era. Rheumatology (Oxford). 2015;54(10):1780-1791.

9. van Riel PL, Renskers L. The Disease Activity Score (DAS) and the Disease Activity Score using 28 joint counts (DAS28) in the management of rheumatoid arthritis. Clin Exp Rheumatol. 2016;34(5 Suppl 101): $\mathrm{S} 40-\mathrm{S} 44$.

10. Anderson J, Caplan L, Yazdany J, et al. Rheumatoid arthritis disease activity measures: American College of Rheumatology recommendations for use in clinical practice. Arthritis Care Res (Hoboken). 2012;64(5): 640-647.

11. Fransen J, van Riel PL. The Disease Activity Score and the EULAR response criteria. Rheum Dis Clin North Am. 2009;35(4):745-757, vii-viii.

12. Mian AN, Ibrahim F, Scott DL, Galloway J; TITRATE study group. Optimal responses in disease activity scores to treatment in rheumatoid arthritis: is a DAS28 reduction of $>1.2$ sufficient? Arthritis Res Ther. 2016;18(1):142

13. Combe B, van Vollenhoven R. Novel targeted therapies: the future of rheumatoid arthritis? Mavrilumab and tabalumab as examples. Ann Rheum Dis. 2013;72(9):1433-1435.

14. Paula FS, Alves JD. Non-tumor necrosis factor-based biologic therapies for rheumatoid arthritis: present, future, and insights into pathogenesis. Biologics. 2014;8:1-12.

15. Larsson I, Bergman S, Fridlund B, Arvidsson B. Patients' dependence on a nurse for the administration of their intravenous anti-TNF therapy: a phenomenographic study. Musculoskeletal Care. 2009;7(2):93-105.

16. Larsson I, Bergman S, Fridlund B, Arvidsson B. Patients' independence of a nurse for the administration of subcutaneous anti-TNF therapy: a phenomenographic study. Int J Qual Stud Health Well-being. 2010;5(2):5146.

17. Singh JA, Saag KG, Bridges SL Jr, et al. 2015 American College of Rheumatology Guideline for the Treatment of Rheumatoid Arthritis. Arthritis Rheumatol. 2016;68(1):1-26.

18. Lewis KB, Stacey D, Squires JE, Carroll S. Shared decision-making models acknowledging an interprofessional approach: a theory analysis to inform nursing practice. Res Theory Nurs Pract. 2016;30(1): 26-43.

19. Tamhane S, Rodriguez-Gutierrez R, Hargraves I, Montori VM. Shared decision-making in diabetes care. Curr Diab Rep. 2015;15(12):112.

20. Marton F. Phenomenography - describing conceptions of the world around us. Instr Sci. 1981;10(2):177-200.

21. Larsson I, Fridlund B, Arvidsson B, Teleman A, Bergman S. Randomized controlled trial of a nurse-led rheumatology clinic for monitoring biological therapy. $J$ Adv Nurs. 2014;70(1):164-175.

22. Larsson I, Fridlund B, Arvidsson B, Teleman A, Svedberg P, Bergman S. A nurse-led rheumatology clinic versus rheumatologist-led clinic in monitoring of patients with chronic inflammatory arthritis undergoing biological therapy: a cost comparison study in a randomised controlled trial. BMC Musculoskelet Disord. 2015;16:354.

23. Marton F, Booth S. Learning and Awareness. Mahwah, NJ: Lawrence Erlbaum Associates; 1997.

24. Dahlgren LO, Fallsberg M. Phenomenography as a qualitative approach in social pharmacy research. J Soc Adm Pharm. 1991;8(4):150-156.

25. Marton F, Pong WY. On the unit of description in phenomenography. High Educ Res Dev. 2005;24(4):335-348.

26. Larsson J, Holmström I. Phenomenographic or phenomenological analysis: does it matter? Examples from a study on anaesthesiologists' work. Int J Qual Stud Health Well-being. 2007;2(1):55-64.

27. Sjöström B, Dahlgren LO. Applying phenomenography in nursing research. $J$ Adv Nurs. 2002;40(3):339-345.
28. Wahlström R, Dahlgren LO, Tomson G, Diwan VK, Beermann B. Changing primary care doctors' conceptions - a qualitative approach to evaluating an intervention. Adv Health Sci Educ Theory Pract. 1997;2(3): 221-236.

29. World Medical Association. World Medical Association declaration of Helsinki: ethical principles for medical research involving human subjects. JAMA. 2013;310(20):2191-2194.

30. Flurey CA, Morris M, Richards P, Hughes R, Hewlett S. It's like a juggling act: rheumatoid arthritis patient perspectives on daily life and flare while on current treatment regimes. Rheumatology (Oxford). 2014;53(4):696-703.

31. Bolge SC, Goren A, Tandon N. Reasons for discontinuation of subcutaneous biologic therapy in the treatment of rheumatoid arthritis: a patient perspective. Patient Prefer Adherence. 2015;9:121-131.

32. Bolge SC, Goren A, Brown D, Ginsberg S, Allen I. Openness to and preference for attributes of biologic therapy prior to initiation among patients with rheumatoid arthritis: patient and rheumatologist perspectives and implications for decision making. Patient Prefer Adherence. 2016;10:1079-1090.

33. Nolla JM, Rodríguez M, Martin-Mola E, et al. Patients' and rheumatologists' preferences for the attributes of biological agents used in the treatment of rheumatic diseases in Spain. Patient Prefer Adherence. 2016;10:1101-1113.

34. Zwikker HE, van Dulmen S, den Broeder AA, van den Bemt BJ, van den Ende $\mathrm{CH}$. Perceived need to take medication is associated with medication non-adherence in patients with rheumatoid arthritis. Patient Prefer Adherence. 2014;8:1635-1645.

35. Louder AM, Singh A, Saverno K, et al. Patient preferences regarding rheumatoid arthritis therapies: a conjoint analysis. Am Health Drug Benefits. 2016;9(2):84-93.

36. Conn VS, Ruppar TM, Enriquez M, Cooper PS. Patient-centered outcomes of medication adherence interventions: systematic review and meta-analysis. Value Health. 2016;19(2):277-285.

37. Pedersen BK, Saltin B. Exercise as medicine-evidence for prescribing exercise as therapy in 26 different chronic diseases. Scand J Med Sci Sports. 2015;25 Suppl 3:1-72.

38. Hernández-Hernández MV, Díaz-González F. Role of physical activity in the management and assessment of rheumatoid arthritis patients. Reumatol Clin. Epub 2016 June 2.

39. Conigliaro P, Triggianese P, Ippolito F, Lucchetti R, Chimenti MS, Perricone R. Insights on the role of physical activity in patients with rheumatoid arthritis. Drug Dev Res. 2014;75 Suppl 1:S54-S56.

40. Konijn NP, van Tuyl LH, Boers M, et al. Effective treatment for rapid improvement of both disease activity and self-reported physical activity in early rheumatoid arthritis. Arthritis Care Res (Hoboken). 2016;68(2): 280-284.

41. Ehrlich-Jones L, Lee J, Semanik P, Cox C, Dunlop D, Chang RW. Relationship between beliefs, motivation, and worries about physical activity and physical activity participation in persons with rheumatoid arthritis. Arthritis Care Res (Hoboken). 2011;63(12):1700-1705.

42. Iversen MD, Scanlon L, Frits M, Shadick NA, Sharby N. Perceptions of physical activity engagement among adults with rheumatoid arthritis and rheumatologists. Int J Clin Rheumatol. 2015;10(2): $67-77$.

43. Veldhuijzen van Zanten JJ, Rouse PC, Hale ED, et al. Perceived barriers, facilitators and benefits for regular physical activity and exercise in patients with rheumatoid arthritis: a review of the literature. Sports Med. 2015;45(10):1401-1412.

44. Loeppenthin K, Esbensen B, Ostergaard M, Jennum P, Thomsen T, Midtgaard J. Physical activity maintenance in patients with rheumatoid arthritis: a qualitative study. Clin Rehabil. 2014;28(3):289-299.

45. Santiago T, Geenen R, Jacobs JW, Da Silva JA. Psychological factors associated with response to treatment in rheumatoid arthritis. Curr Pharm Des. 2015;21(2):257-269.

46. van Os S, Norton S, Hughes LD, Chilcot J. Illness perceptions account for variation in positive outlook as well as psychological distress in rheumatoid arthritis. Psychol Health Med. 2012;17(4):427-439. 
47. Flurey CA, Hewlett S, Rodham K, White A, Noddings R, Kirwan JR. Identifying different typologies of experiences and coping strategies in men with rheumatoid arthritis: a Q-methodology study. BMJ open. 2016;6(10):e012051.

48. Kostova Z, Caiata-Zufferey M, Schulz PJ. The impact of social support on the acceptance process among RA patients: a qualitative study. Psychol Health. 2014;29(11):1283-1302.

49. Brandstetter S, Hertig S, Loss J, Ehrenstein B, Apfelbacher C. "The lesser of two evils..." - views of persons with rheumatoid arthritis on medication adherence: a qualitative study. Psychol Health. 2016;31(6): 675-692.

50. Betegnie AL, Gauchet A, Lehmann A, et al. Why do patients with chronic inflammatory rheumatic diseases discontinue their biologics? An assessment of patients' adherence using a self-report questionnaire. J Rheumatol. 2016;43(4):724-730.

51. Zuidema RM, Repping-Wuts H, Evers AW, Van Gaal BG, Van Achterberg T. What do we know about rheumatoid arthritis patients' support needs for self-management? A scoping review. Int J Nurs Stud. 2015;52(10):1617-1624.

52. Walter MJ, Van't Spijker A, Pasma A, Hazes JM, Luime JJ. Focus group interviews reveal reasons for differences in the perception of disease activity in rheumatoid arthritis. Qual Life Res. 2017;26(2):291-298.

53. Feldthusen C, Dean E, Forsblad-d'Elia H, Mannerkorpi K. Effects of person-centered physical therapy on fatigue-related variables in persons with rheumatoid arthritis: a randomized controlled trial. Arch Phys Med Rehabil. 2016;97(1):26-36.
54. Ahlstrand I, Björk M, Thyberg I, Börsbo B, Falkmer T. Pain and daily activities in rheumatoid arthritis. Disabil Rehabil. 2012;34(15): 1245-1253.

55. Poh LW, He HG, Lee CS, Cheung PP, Chan WC. An integrative review of experiences of patients with rheumatoid arthritis. Int Nurs Rev. 2015; 62(2):231-247.

56. Bergsten U, Bergman S, Fridlund B, Arvidsson B. "Striving for a good life" - the management of rheumatoid arthritis as experienced by patients. Open Nurs J. 2011;5:95-101.

57. Stamm T, Lovelock L, Stew G, et al. I have mastered the challenge of living with a chronic disease: life stories of people with rheumatoid arthritis. Qual Health Res. 2008;18(5):658-669.

58. Grønning K, Lomundal B, Koksvik HS, Steinsbekk A. Coping with arthritis is experienced as a dynamic balancing process. A qualitative study. Clin Rheumatol. 2011;30(11):1425-1432.

59. Voshaar MJ, Nota I, van de Laar MA, van den Bemt BJ. Patient-centred care in established rheumatoid arthritis. Best Pract Res Clin Rheumatol. 2015;29(4-5):643-663.

60. Lincoln YS, Guba EG. Naturalistic Inquiry. Beverly Hills, CA: Sage; 1985.

61. Polit DF, Beck CT. Nursing Research: Generating and Assessing Evidence for Nursing Practice. 10th ed. Philadelphia, PA: Wolters Kluwer; 2016
Patient Preference and Adherence

\section{Publish your work in this journal}

Patient Preference and Adherence is an international, peer-reviewed, open access journal that focuses on the growing importance of patient preference and adherence throughout the therapeutic continuum. Patient satisfaction, acceptability, quality of life, compliance, persistence and their role in developing new therapeutic modalities and compounds to optimize

\section{Dovepress}

clinical outcomes for existing disease states are major areas of interest for the journal. This journal has been accepted for indexing on PubMed Central. The manuscript management system is completely online and includes a very quick and fair peer-review system, which is all easy to use. Visit http://www. dovepress.com/testimonials.php to read real quotes from published authors. 